\title{
Sertraline exposure leads to small left heart syndrome in adult mice
}

\author{
Sarah E. Haskell', Gregory M. Hermann', Benjamin E. Reinking', Kenneth A. Volk'1', Veronica A. Peotta', Vivian Zhu' and \\ Robert D. Roghair ${ }^{1}$
}

BACKGROUND: Sertraline, a selective serotonin reuptake inhibitor (SSRI), is the most commonly prescribed therapy for maternal depression. Epidemiologic studies have linked SSRI exposure with decreased fetal growth, altered autonomic regulation, and cardiac malformations. We hypothesized that SSRI exposure decreases left-ventricular (LV) volumes and increases adult sympathetic nervous system activation, resulting in increased adult heart rates.

METHODS: C57BL/6 mice received saline or sertraline (5 or $15 \mathrm{mg} / \mathrm{kg} /$ day i.p.) on postnatal days 1-14. Adult phenotypes were assessed at 5 mo.

RESULTS: Sertraline-exposed mice had smaller LV internal diameters in diastole (control $4.0 \pm 0.1 \mathrm{~mm}, \mathrm{SSRI} 3.7 \pm 0.1 \mathrm{~mm}$, $P<0.05$ ), decreased stroke volumes (control $46 \pm 2.6 \mu$, SSRI 37 $\pm 2.3 \mu \mathrm{l}, P<0.05$ ), higher heart rates (control $530 \pm 13$ beats per minute (bpm), SSRI $567 \pm 6 \mathrm{bpm}, P<0.05)$, and increased urinary excretion of noradrenaline (control $174 \pm 29.4 \mathrm{ng} / \mathrm{ml}$, SSRI $276 \pm 35.1 \mathrm{ng} / \mathrm{ml}, P<0.05)$. These changes were associated with increased cerebral serotonin transporter (5-HTT) expression. CONCLUSION: Neonatal sertraline exposure causes longterm changes in cardiac morphology and physiology. We speculate that early-life SSRI exposure impairs cardiomyocyte growth and central serotonin signaling, leading to a small left heart syndrome in adult mice.

D uring the past $4 \mathrm{y}$, selective serotonin reuptake inhibitors (SSRIs) have been the most commonly prescribed antidepressants in the United States (1). Annual prescriptions for sertraline have increased dramatically from 10.8 million in 2006 to 35.7 million in 2010 (1). Similarly, SSRI use during pregnancy has been steadily increasing and is now estimated to affect $6.2 \%$ of pregnancies (2-5). With more than 4 million annual live births in the United States (http://www.census.gov), a significant number of pregnancies are being affected by SSRI therapy.

Pharmacokinetic and epidemiologic studies have shown that significant fetal exposure occurs during maternal SSRI therapy (6-8). Intrauterine exposure is associated with decreased fetal growth, impaired neonatal adaptation, and increased risk of cardiac malformations (7-9). Although the neonatal effects from intrauterine SSRI exposure are well established, the long-term effects of exposure remain unclear. Prospective human studies are beginning to demonstrate persistent changes in hypothalamic regulation, heart rate responses to pain, and behavior in children exposed to maternal SSRI therapy (10-12).

Animal studies have demonstrated that neonatal SSRI exposure suppresses adult serotonergic signaling and elicits features of depression $(13,14)$. In particular, neonatal SSRI exposure elicits a persistent downregulation in midbrain expression of tryptophan hydroxylase, the rate-limiting enzyme in serotonin production (15). Beyond effects on mood, midbrain serotonergic neurons project widely, including prominent input to the hypothalamus and rostral ventrolateral medulla $(16,17)$. In these regions, serotonin receptor stimulation blunts the cardiovascular responses to stress, suggesting a sympatho-inhibitory effect of central serotonergic signaling $(16,17)$.

Due to the high rate of in utero exposure, postmarketing surveillance of the SSRIs has been extensive. In 2005, GlaxoSmithKline reported an increased risk of congenital heart disease in infants of mothers taking paroxetine, leading to the US Food and Drug Administration changing the paroxetine product label to pregnancy category D (indicating studies in pregnant women have demonstrated a risk to the fetus) (9). Many subsequent studies have been completed supporting an association between maternal SSRI therapy and ventricular septal defects in infants (18-21).

The association between SSRI exposure and cardiac defects is further supported by decades of research highlighting the importance of regulated serotonin (5-HT) signaling in cardiomyocyte proliferation and maturation. Sari and Zhou investigated the effects of 5-HT and paroxetine on fetal rat cardiomyocyte proliferation. They found that $5-\mathrm{HT}$ concentration at a physiologic level, $4 \mu \mathrm{mol} / \mathrm{l}$, permitted optimal proliferation of heart cells as indicated by the number of 5-bromo-deoxyuridine immunoreactive cells (22). Lower and higher concentrations of 5-HT and 5-HT reuptake inhibition by paroxetine decreased proliferation (22). Likewise, 5- $\mathrm{HT}_{2 \mathrm{~B}}$ knockout mice are born with cardiac hypoplasia resulting from impaired proliferation and a decrease in cardiomyocyte size (23). Of note, whereas human cardiomyocyte proliferation is essentially complete at delivery, in mice, cardiomyocyte growth and proliferation are robust for $14 \mathrm{~d}$ after delivery $(24,25)$. We hypothesized that SSRI exposure decreases left-ventricular (LV) volumes and 
increases adult sympathetic nervous system activation, resulting in increased adult heart rates.

\section{RESULTS}

\section{Exposure Model}

Pup weights at initiation of sertraline exposure (day (d)1) were similar. By the final day of exposure (d14), sertraline-exposed mice had significantly decreased weights (control $7.35 \pm 0.15 \mathrm{~g}$, sertraline $6.8 \pm 0.12 \mathrm{~g}, P=0.011$ ). Twenty-four hours after the final exposure, sertraline-exposed mice had plasma levels of 18.9 $\pm 4.4 \mathrm{ng} / \mathrm{ml}(n=7)$ and whole-brain levels of $370 \pm 39 \mathrm{ng} / \mathrm{g}(n$ $=6$ ). Sertraline-exposed mice achieved normal adult weights by $5 \mathrm{mo}$ (control $31.2 \pm 1.0 \mathrm{~g}$, sertraline $29.9 \pm 0.9 \mathrm{~g}$ ). Because no hemodynamic differences were observed between the 5 and $15 \mathrm{mg} / \mathrm{kg} /$ day sertraline groups, they are presented as one group.

\section{Increased Heart Rates in Adult Mice}

Overall mean heart rates were obtained by first calculating an individual mouse's hemodynamic parameters from the capture

a

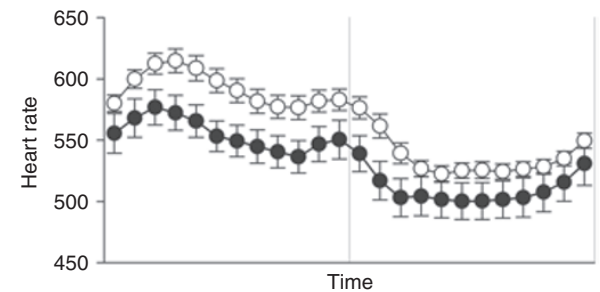

b

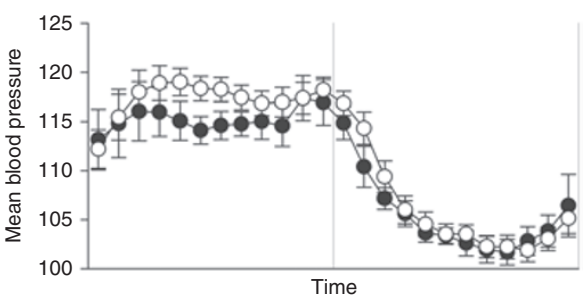

C

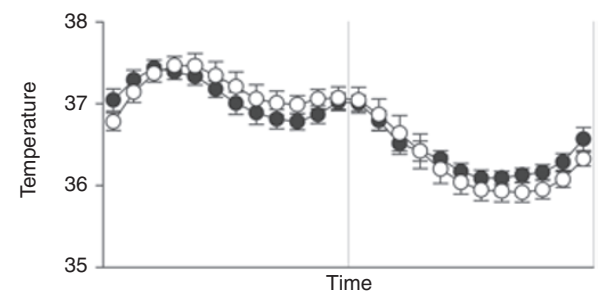

d

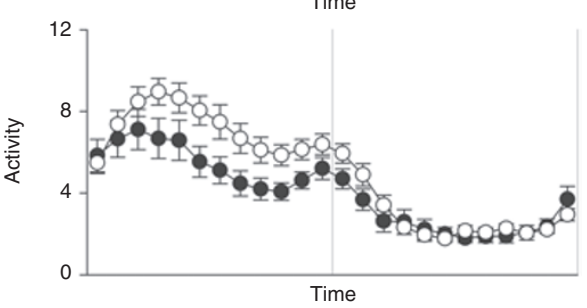

Figure 1. Neonatal sertraline exposure increases adult heart rate and activity level, but not temperature or blood pressure. Radiotelemetry was used to monitor control mice (black circles, $n=29$ mice from 17 litters) and sertraline-exposed mice (white circles, $n=17$ mice from 12 litters). Hourly averages are shown for the dark cycle (1800-0600 hours, left side of $x$-axis) and light cycle (0600-1700 hours, right side of $x$-axis). (a) Sertraline exposure increased adult heart rates. There were no differences in (b) mean blood pressure or (c) temperature between sertraline-exposed mice and controls. (d) Sertraline-exposed mice had increased activity levels. of telemetry data every $5 \mathrm{~min}$ for 60 continuous hours and then averaging these values across the group. On the basis of this comprehensive analysis, sertraline-exposed mice had higher heart rates than controls (control $530 \pm 13$ vs. SSRI $567 \pm 6, P<0.01$ by Student's $t$-test) (Figure 1a). An in-depth analysis of the data by repeated-measures ANOVA showed that significant interactions occurred between exposure and time of day. On post hoc testing, SSRI exposure increased heart rates from 1800 through 0800 hours $(P<0.05)$. Compared with controls, sertraline-exposed male mice had similar arterial pressures (Figure 1b) and temperatures (Figure 1c). Sertraline-exposed mice had higher overall activity levels than control mice (control $3.9 \pm 0.4$, sertraline $5.1 \pm$ $0.3, P<0.05$ by Student's $t$-test). By repeated measures ANOVA, there was likewise an overall effect of SSRI on activity level $(P<$ 0.05 ) (Figure 1d), with significant differences noted on post hoc testing from 2000 through 0400 hours and at 0600-0700 hours for SSRI vs. control.

\section{Markers of Sympathetic Activation}

As shown in Figure 1, mice exposed to sertraline had increased heart rates and increased activity levels, most prominent during
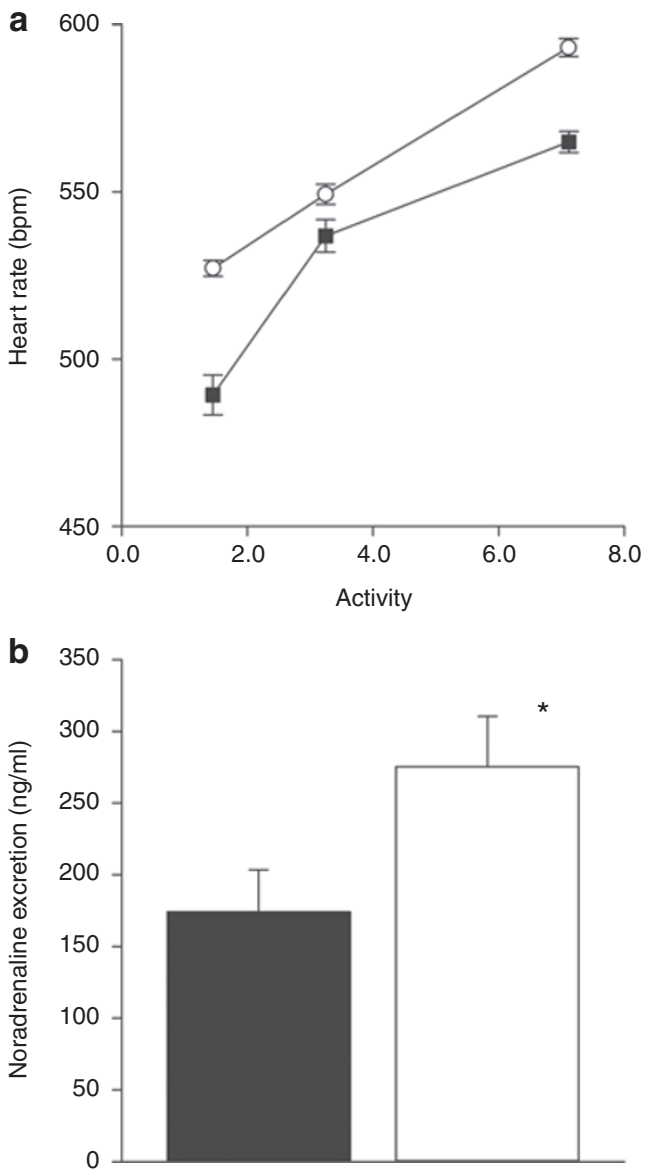

Figure 2. Sertraline-exposed mice had higher heart rates when controlled for activity level and increased urinary excretion of noradrenaline. (a) Tertiles for activity level are demonstrated. For a given activity level, sertralineexposed mice (white circles) had higher heart rates than control mice (black squares). (b) Sertraline-exposed mice (white bar, $n=17$ mice from 11 litters) also had increased urinary excretion of noradrenaline as compared with control mice (black bar, $n=17$ mice from 11 litters). ${ }^{*} P<0.05$ vs. control. 
Table 1. MBP by telemetry following injections with prazosin and chlorisondamine

\begin{tabular}{lcc}
\hline Measurement & Saline $(n=5)$ & Sertraline $(n=16)$ \\
\hline Prazosin $(1 \mathrm{mg} / \mathrm{kg})$ & & \\
MBP, mm Hg & $89 \pm 2$ & $79 \pm 2^{*}$ \\
MBP, \% baseline & $74 \pm 1$ & $64 \pm 2^{*}$ \\
Chlorisondamine $(2.5 \mathrm{mg} / \mathrm{kg})$ & & \\
MBP, mm Hg & $78 \pm 3$ & $72 \pm 3$ \\
MBP, \% baseline & $65 \pm 2$ & $61 \pm 3$ \\
\hline
\end{tabular}

$M B P$, mean blood pressure.

${ }^{*} P<0.05$.

Table 2. Mean HR by telemetry following injections with sympathetic and parasympathetic antagonists

\begin{tabular}{lcc}
\hline Measurement & $\begin{array}{c}\text { Saline, } \\
10 \mathrm{ml} / \mathrm{kg} / \mathrm{d}(n=10)\end{array}$ & $\begin{array}{c}\text { Sertraline, } \\
5 \mathrm{mg} / \mathrm{kg} / \mathrm{d}(n=11)\end{array}$ \\
\hline Prazosin $(1 \mathrm{mg} / \mathrm{kg})$ & & \\
HR, bpm & $534 \pm 92$ & $518 \pm 14$ \\
HR, \% baseline & $99 \pm 13$ & $100 \pm 13$ \\
Scopolamine $(2 \mathrm{mg} / \mathrm{kg})$ & & \\
HR, bpm & $613 \pm 13$ & $633 \pm 20$ \\
HR, \% baseline & $120 \pm 3^{*}$ & $120 \pm 4^{*}$ \\
Metoprolol (mg/kg) & & \\
HR, bpm & $504 \pm 9$ & $486 \pm 35$ \\
HR, \% baseline & $99 \pm 3$ & $91 \pm 7$
\end{tabular}

bpm, beats per minute; $H R$, heart rate.

${ }^{*} P<0.05$.

the dark cycle (1800-0600 hours). For a given activity level, sertraline-exposed mice had persistently higher heart rates than control mice (Figure 2a). Sertraline-exposed mice also had increased urinary noradrenaline excretion (Figure $2 b$ ). To test the hypothesis that sertraline-exposed mice had increased cardiac sympathetic tone, recordings were obtained following the administration of sympathetic and/or parasympathetic antagonists. Mice exposed to sertraline had exaggerated hypotensive responses to prazosin (Table 1). Following chlorisondamine injections, sertraline-exposed mice tended again to have decreased blood pressures, but this was not statistically significant (Table 1). There were no significant differences in heart rate responses to sympathetic and parasympathetic blockade between control mice and sertraline-exposed mice (Table 2). To further quantify resting autonomic tone, beat-to-beat heart rate variability (HRV) was assessed. Although no significant differences in pulse interval variability were seen by time domain analysis (data not shown), frequency domain analysis revealed significantly increased very low frequency (VLF) pulse interval variability in sertraline-exposed mice (Figure 3a), which was almost entirely eliminated by chlorisondamine (Figure $3 \mathbf{b}$ ). Frequency domain analysis by electrocardiogram telemeter tracings revealed significantly increased spectral power at all frequencies in sertraline-exposed mice as compared with
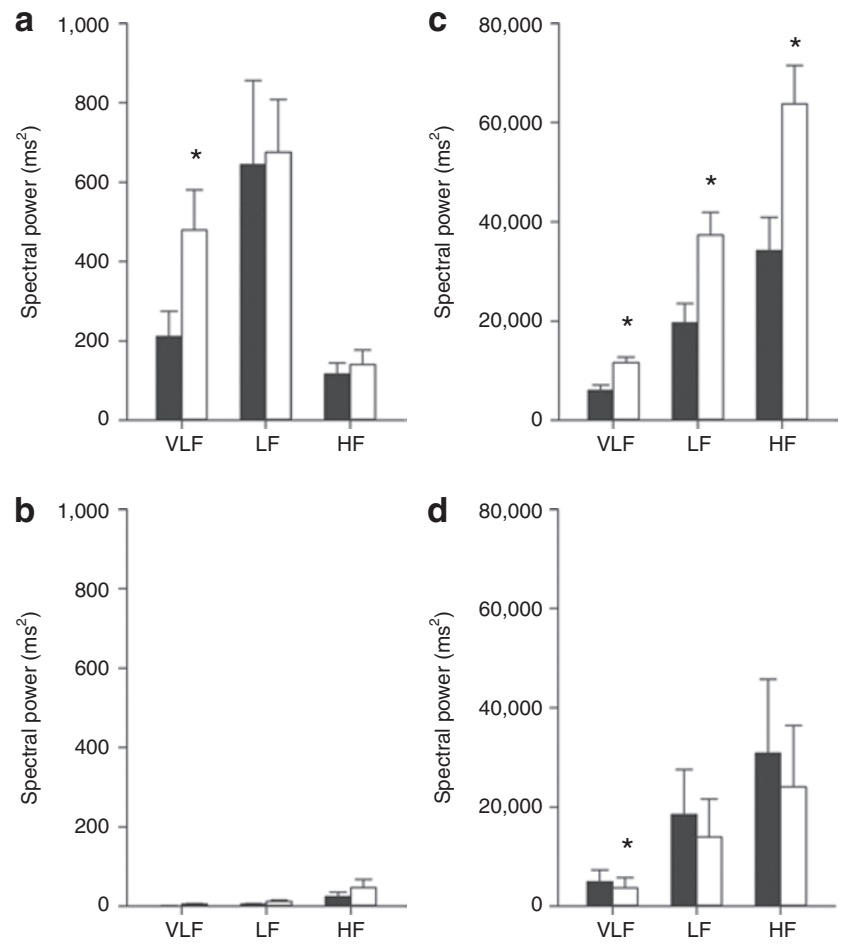

Figure 3. Sertraline exposure increased low-frequency heart rate variability (HRV). (a) Sertraline-exposed mice (white bars, $n=12$ mice from 7 litters) had significantly increased very low frequency (VLF) HRV by carotid telemetry as compared with control mice (black bars, $n=6$ mice from five litters). (b) Following chlorisondamine, VLF and low-frequency (LF) spectral power were almost entirely eliminated. (c) By electrocardiography, sertraline-exposed mice had increased VLF, LF, and high-frequency (HF) spectral power as compared with control mice. (d) After metoprolol, sertraline-exposed mice had significantly decreased VLF spectral power, but all spectral power was reduced. ${ }^{*} P<0.05$ vs. control.

Table 3. Baseline echocardiograms for adult male mice

\begin{tabular}{lcc}
\hline Echocardiogram measurement & $\begin{array}{c}\text { Control } \\
(n=14)\end{array}$ & $\begin{array}{c}\text { Sertraline } \\
(n=17)\end{array}$ \\
\hline Shortening fraction $(\%)$ & $37 \pm 2.1$ & $35 \pm 1.6$ \\
Ejection fraction $(\%)$ & $66 \pm 2.7$ & $64 \pm 2.1$ \\
Interventricular septum, diastole $(\mathrm{mm})$ & $0.8 \pm 0.05$ & $0.9 \pm 0.04$ \\
LV posterior wall, diastole $(\mathrm{mm})$ & $1.0 \pm 0.1$ & $1.0 \pm 0$ \\
LV posterior wall, systole $(\mathrm{mm})$ & $1.5 \pm 0.1$ & $1.5 \pm 0.1$ \\
LV mass $(\mathrm{mg})$ & $147 \pm 7.5$ & $139 \pm 6.7$ \\
LV internal diameter, diastole $(\mathrm{mm})$ & $4.0 \pm 0.1$ & $3.7 \pm 0.1^{*}$ \\
LV internal diameter, systole $(\mathrm{mm})$ & $2.6 \pm 0.1$ & $2.4 \pm 0.1$ \\
LV volume, diastole $(\mu \mathrm{l})$ & $71 \pm 4.3$ & $59 \pm 4.2$ \\
LV volume, systole $(\mu \mathrm{l})$ & $25 \pm 2.7$ & $22 \pm 2.4$ \\
Stroke volume $(\mu \mathrm{l})$ & $46 \pm 2.6$ & $37 \pm 2.3^{*}$ \\
\hline
\end{tabular}

$\mathrm{LV}$, left-ventricular.

${ }^{*} P<0.05$.

control mice (Figure 3c). Following metoprolol injections, sertraline-exposed mice had a significant decrease in VLF spectral power (Figure 3d) and nonsignificant decreases in other spectral bands. 


\section{Sertraline exposure and physiology}

a
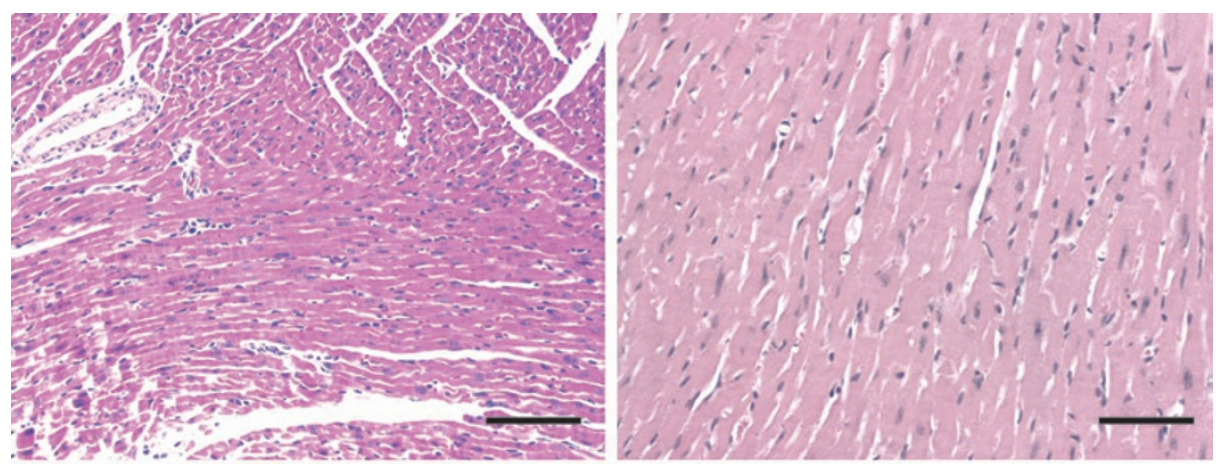

b
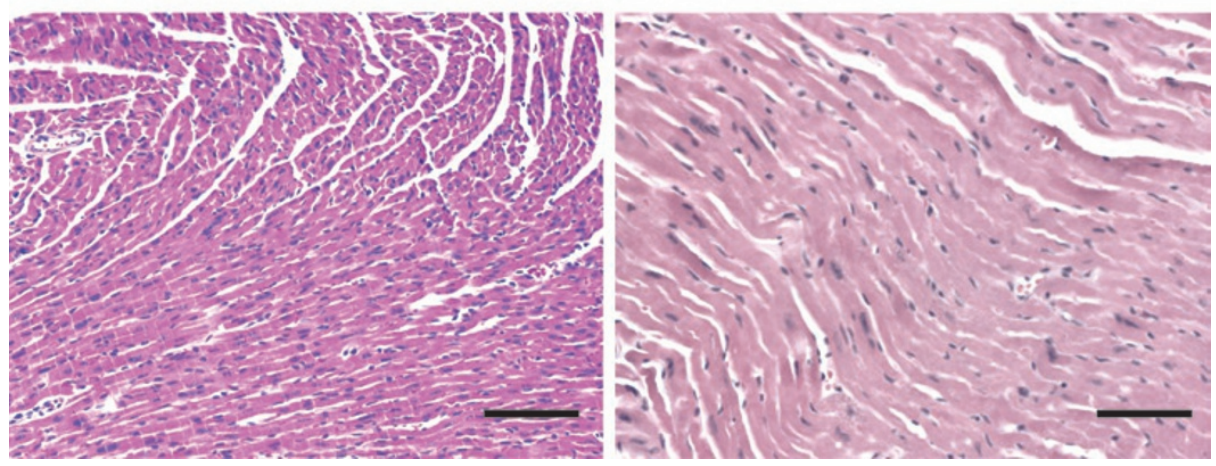

Figure 4. Sertraline-exposed mice had no differences in morphology as compared with control mice on hematoxylin-eosin staining. (a) Sertralineexposed mice and (b) control mice had normal cardiac structure as neonates (left, $n=4$ neonatal SSRI, $n=4$ neonatal controls) and as adults (right, $n=6$ $\mathrm{SSRI}, n=6$ controls). Bar $=100 \mu \mathrm{m}$. SSRI, selective serotonin reuptake inhibitor.

\section{Decreased Stroke Volume in Adult Mice}

Sertraline-exposed mice had significantly smaller LV internal diameters in diastole and decreased stroke volumes (Table 3). No differences were observed in fractional shortening $(P=0.45)$ or predicted LV mass $(P=0.42)$ (Table 3$)$. No adult mouse had a septal defect discovered by echocardiography. Although no right-sided measurements were recorded, the interventricular septum was normally shaped in all echocardiograms, and there was no evidence of pulmonary hypertension. No differences were observed between the groups in overall morphology on the basis of hematoxylin-eosin staining (Figure 4).

\section{Neonatal Sertraline Exposure Alters Central Serotonergic Signaling}

Quantitative PCR studies demonstrated that neonatal sertraline exposure leads to a 2-3 fold increase in 5-HTT in the cortex and midbrain in adults as compared with control mice (Figure 5a). The serotonin receptor $5-\mathrm{HT}_{2 \mathrm{~B}}$ had decreased expression in the cortex as compared with that of control mice (Figure $5 b$ ).

\section{DISCUSSION}

With up to $6.2 \%$ of pregnancies influenced by SSRIs (2-5), it is crucial to investigate the consequences of fetal SSRI exposure. To our knowledge, this is the first study that investigated the long-term cardiovascular effects from analogous neonatal sertraline exposure. Because the majority of previous animal studies have focused on behavioral aspects, this is a novel area with no preclinical studies for comparison. Likewise, SSRI therapy was introduced to obstetrical care only over the past decade, and there are no data on adult cardiovascular phenotypes in exposed humans. The key findings in our model were increased heart rates, increased urinary noradrenaline excretion, and decreased stroke volumes. The cause-effect relationship between the increased heart rates and decreased stroke volumes is not clear, but we hypothesize it may be from increased sympathetic tone, altered vascular capacitance, and/ or decreased cardiomyocyte proliferation.

One hypothesis is that the increased heart rates are related to increased central sympathetic outflow. The increased urinary noradrenaline excretion, in combination with increased heart rates and increased activity levels, supports this hypothesis. The increased expression of 5-HTT in the cortex and midbrain demonstrates a rebound increase in the serotonin transporter protein in adults following neonatal 5-HTT inhibition during SSRI exposure. This increase in 5-HTT expression may lead to decreased serotonergic tone and increased sympathetic activation. HRV analysis was developed to assess sympathetic and parasympathetic influences in humans. There is a large body of evidence to suggest that autonomic imbalance, in which the sympathetic system is hyperactive and the parasympathetic system is hypoactive (or increased low frequency:high frequency ratio), is associated with an increased risk of cardiovascular disease (26). Sertraline-exposed mice had increased VLF spectral power, but the role of VLF power is not entirely understood. In addition, if our findings were entirely related to sympathetic tone, then we would have observed significant differences in our heart rate responses following sympathetic blockade. One way to further analyze and support the 

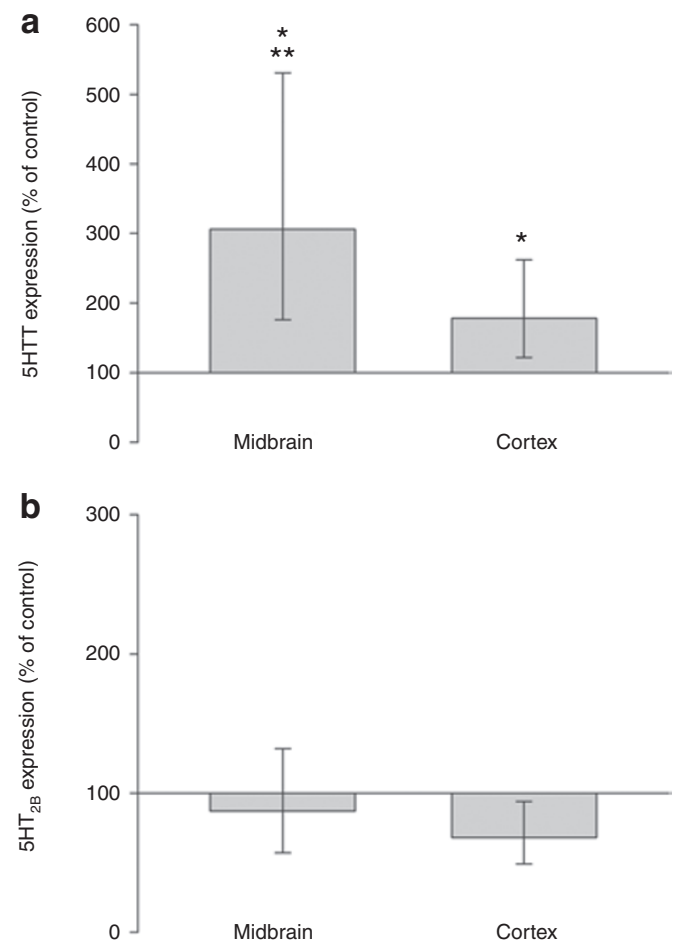

Figure 5. Sertraline-exposed mice have increased expression of the serotonin transporter protein (5-HTT). PCR was performed on midbrain and cerebral cortex homogenates obtained from control and SSRI-exposed mice (gray bars). Expression levels of the serotonin transporter protein and serotonin receptor $5-\mathrm{HT}_{2 \mathrm{~B}}$ were quantified and compared with those in control mice. (a) Midbrain and cerebral cortex expression of 5-HTT mRNA is significantly increased in SSRI-exposed male mice than in control mice. (a) Midbrain 5-HTT expression is significantly increased as compared with that in the cortex. (b) No differences were observed in expression of $5-\mathrm{HT}_{2 \mathrm{~B}}$ receptors between brain regions or between sertraline-exposed mice and control mice. $n=7-10$ mice from $5-10$ litters. ${ }^{*} P<0.05$ vs. control. ${ }^{*} P<<0.05$ vs. cortex. SSRI, selective serotonin reuptake inhibitor.

hypothesis that sertraline-exposed mice have increased sympathetic activation would be to measure renal nerve sympathetic activity in these mice.

An alternative hypothesis for increased heart rates and decreased stroke volumes is altered vascular capacitance. Sertraline-exposed mice had exaggerated responses to prazosin, an $\alpha$-antagonist, suggesting altered vascular capacitance. With no other structural differences noted by echocardiograms and no differences noted on hematoxylin-eosin staining, the increased heart rates observed in our mice may be purely related to decreased passive filling. Serotonin's effects on vascular tone are mediated by multiple receptors that are located on vascular smooth muscle cells. Ungvari et al. (27) demonstrated that fluoxetine elicited substantial dilation of isolated skeletal muscle arterioles and small cerebral arteries of rats, and it is possible that early-life SSRI exposure permanently altered vascular tone as a result of altered gene expression.

In addition, recent studies have demonstrated a direct effect of serotonin on the developing heart. The $5-\mathrm{HT}_{2 \mathrm{~B}}$ receptor is expressed in cardiovascular tissues and is the only serotonergic receptor known to be involved in cardiac proliferating cells (28).
5- $\mathrm{HT}_{2 \mathrm{~B}}$ null mice have heart defects with high midgestation lethality $(29,30)$. Newborn $5-\mathrm{HT}_{2 \mathrm{~B}}$ knockout mice develop cardiac dilation with cardiac hypoplasia resulting from impaired proliferation and a decrease in cardiomyocyte size $(29,30)$. Although no differences were detected on hematoxylin-eosin staining or in overall LV mass, sertraline-exposed mice had smaller LV internal diameters in diastole and smaller stroke volumes. Our PCR data demonstrate decreased expression of $5-\mathrm{HT}_{2 \mathrm{~B}}$ receptors in the sertraline-exposed adult mice, suggesting impaired central serotonergic tone. Further studies on isolated neonatal cardiac myocytes are needed to assess impaired growth or proliferation as an etiology of the diminished stroke volumes. Further studies with echocardiograms at earlier time points will also be crucial to determining the onset and trajectory of the diminished stroke volumes. These studies must focus on changes in neonatal mice during a time of rapid cardiomyocyte development that establishes adult myocyte endowment.

The hyperactivity we measured could be secondary to increased sympathetic tone but is a well-described finding in SSRI exposure models $(15,31,32)$. Zeskind and Stephens (33) also found newborns exposed to intrauterine SSRIs to have higher activity levels. The etiology of this increased locomotor activity is currently an area of active investigation. SSRI exposure may trigger region-specific changes in serotonin production or receptor density, which could influence physical activity $(34,35)$. Of note, the increased heart rates in sertraline-exposed mice were not solely due to activity. When we compared heart rates at specific activity levels, the sertralineexposed mice continued to have higher heart rates than control mice. This hyperdynamic, hyperactive state is consistent with the post-SSRI hypermetabolic state we recently described in identically exposed male and female mice (32).

It is important to emphasize why we utilized a neonatal exposure model in mice to mimic late intrauterine SSRI exposure in humans. We were interested in this window because up to $6 \%$ of infants are exposed to SSRIs during fetal development (2-5). Neonates are rarely prescribed SSRIs, and there are typically undetectable SSRI levels in breast milk. In humans, the embryonic stage of cardiac development is complete and the heart has taken its adult shape by the end of the first trimester. The subsequent fetal stage of cardiac development largely establishes the adult complement of myocytes, given that mononucleated cardiomyocytes begin to terminally differentiate into binucleated cells (36). At the time of delivery, $>70 \%$ of human cardiomyocytes have withdrawn from the cell cycle, and the myocyte turnover rate falls to less than $1 \%$ per year (37). Postnatal mice still undergo growth and proliferation of cardiomyocytes during the first $14 \mathrm{~d}$ of life $(24,25)$. To capture the terminal proliferative phase of cardiomyocyte development without eliciting teratogenic effects from embryonic exposure, we utilized a targeted neonatal exposure that captures a window of susceptibility analogous to the third trimester in humans. For example, Noorlander et al (23) demonstrated the teratogenic effects of earlier exposure as mice exposed to fluoxetine during the intrauterine phase of cardiac development had significantly decreased survival during the preweaning period. Eighty-one percent of mice treated 
prenatally with fluoxetine died and were found to have dilated cardiomyopathy (23), thus eliminating the use of combined intrauterine and neonatal exposure in our experiments.

In our model, we injected mice during the first $14 \mathrm{~d}$, and the sertraline dose we used led to levels comparable with typical human levels $(38,39)$. Further supporting the biologic relevance of our model, we noted mild neonatal growth restriction, which is consistent with the lower birth weights seen in SSRI-exposed infants $(4,40)$. Regarding the clinical relevance of the $5 \mathrm{mg} / \mathrm{kg}$ dose of sertraline that we utilized, we have previously reported plasma levels $2 \mathrm{~h}$ after injection of $71.8 \pm 1.3 \mathrm{ng} / \mathrm{ml}$ and plasma levels $12 \mathrm{~h}$ after injection of $13.1 \pm 0.6 \mathrm{ng} / \mathrm{ml}$ (32). On the basis of these levels, estimated peak and trough concentrations were 101 and $1.7 \mathrm{ng} / \mathrm{ml}$, respectively. Our projected peak concentration approximates that seen in pregnancy, and our projected trough concentration approximates umbilical cord levels (32). Although our drug levels were comparable with maternal levels during pregnancy, the placenta provides a partial barrier to fetal exposure. It is therefore possible that the lowest dose we utilized exceeds clinical exposure, and the relatively high exposure seen in our model may explain the lack of dose-response.

\section{Limitations}

A major caveat to our study is the lack of clinical correlates. Although multiple studies have been performed to determine if SSRIs are cardiac teratogens, no clinical studies have looked at long-term cardiovascular effects from neonatal exposure. Our findings of exaggerated hemodynamic responses to sympathetic blockade that suggest increased sympathetic tone could be reinforced by measuring renal nerve sympathetic activity. We investigated only male mice, but previous studies suggest similar phenotypes may be present in female mice.

\section{Conclusion}

There is converging evidence in our model that neonatal SSRI exposure causes long-standing cardiovascular changes including increased heart rates, decreased stroke volumes, and increased urinary noradrenaline excretion in adult male mice. Human studies will be indispensable in establishing the clinical implications of these murine studies. With up to $6 \%$ of pregnancies complicated by intrauterine SSRI exposure, the long-term effects of maternal SSRI therapy need to be investigated further. In our study, increased sympathetic tone is the most likely hypothesis for our findings, but we cannot exclude the etiology of our long-term cardiovascular changes as being multifactorial. Although maternal antidepressant therapy has a critical role in the preservation of fetal and maternal health, additional data are needed to elucidate the long-term risks of intrauterine antidepressant exposure.

\section{METHODS}

\section{Animal Model}

All procedures were approved by the University of Iowa Animal Care and Use Committee. Pregnant C57BL/6 mice (Jackson Laboratory, Bar Harbor, ME) were allowed to deliver naturally. Pups were culled into litters of six and included male and female mice. Within each litter, pups were randomized to receive intraperitoneal saline $(10 \mathrm{ml} / \mathrm{kg} /$ day $)$ or sertraline ( 5 or $15 \mathrm{mg} / \mathrm{kg} /$ day). Injection volumes were the same in each group $(10 \mathrm{ml} / \mathrm{kg} /$ day). Injections were administered from postnatal day 1 to 14 to encompass a developmental window similar to the third trimester of human pregnancy. When normalized by body surface area, $15 \mathrm{mg} / \mathrm{kg} /$ day sertraline corresponds to the upper range of clinical dosing (human dose of $200 \mathrm{mg} /$ day). The lower $5 \mathrm{mg} / \mathrm{kg}$ dose was chosen to reflect exposure under the assumption that maternal therapy is prescribed at the lowest effective dose (typically $50-100 \mathrm{mg} /$ day). Pups were weighed daily during injections, and sertraline-exposed and control pups were nursed by the same mother to minimize environmental influences on growth and development. Weights were obtained again at time of weaning $(21 \mathrm{~d})$ and 5 mo of age. Plasma and brain sertraline levels were assayed in the $5 \mathrm{mg} / \mathrm{kg} /$ day sertraline-exposed group after the final injection. Mice were anesthetized with isoflurane and then killed by exsanguination. The liver was excised and $600-750 \mu$ of blood was collected. Plasma was stored at $-20^{\circ} \mathrm{C}$ until analysis. Whole-brain tissue was dissected and stored at $-80^{\circ} \mathrm{C}$. Analysis by gas chromatography was performed at NMS Labs (Willow Grove, PA).

Echocardiograms. Beginning at 5 mo of age, baseline echocardiograms were performed on male mice who received the $5 \mathrm{mg} / \mathrm{kg}$ sertraline injections and control mice. The mice were anesthetized using isoflurane and placed on a warming platform. Anesthesia was titrated to minimize movement yet maintain heart rate between 450 and 600 beats per minute. Temperature was monitored with a rectal thermometer and maintained between 35 and $36^{\circ}$ Celsius. Echocardiograms were performed using the VisualSonics Vevo 2100 High Resolution Imaging System and software (VisualSonics, Toronto, Ontario, Canada) by an investigator blinded to group assignment. Parasternal long axis, parasternal short axis, and apical four-chamber views were obtained in all animals. M-mode recordings were obtained of the right and left ventricles in the parasternal short axis view at the level of the LV papillary muscles. Measurements were made of the interventricular septum thickness in diastole and systole, LV internal dimension in diastole and systole, and LV posterior wall thickness in diastole and systole. These measurements were then used to calculate the LV ejection fraction and fraction shortening, LV diastolic and systolic volumes, and LV mass. Calculations were made by the Vevo 2100 software. Measurements and calculations were made in accordance with the American Society for Echocardiography Guidelines (41). Volumes were calculated based on the formulas of Teicholz et al. as validated in Kronik et al. study (42).

\section{Telemetry Recordings}

At 5 mo, carotid radiotelemeters (PA-C10: Data Sciences International, St. Paul, MN) were implanted in male mice as previously described (43). All telemetry implants were performed using isoflurane titrated based upon respiratory status and pedal reflex. Following a 7-d recovery, arterial waveforms were sampled for $10 \mathrm{~s}$ every $5 \mathrm{~min}$ over a total of $60 \mathrm{~h}$ (an uninterrupted series of three dark cycles and two light cycles). We subsequently utilized electrocardiogram telemeters to further assess heart rate, activity levels, and temperature, avoiding unilateral carotid artery ligation on male mice injected with $5 \mathrm{mg} / \mathrm{kg}$ /day sertraline or saline as neonates. These electrocardiogram telemeters (TA-F10; Data Sciences International) were implanted with the transmitter secured within the peritoneum. Mice were anesthetized and placed supine on a heated surgical table. Limbs were secured with tape and the abdomen was shaved and disinfected with an alcohol swab. A $1.5-2 \mathrm{~cm}$ midline incision through the skin and abdominal wall was made. The transmitter was placed in the peritoneal cavity, parallel to the long axis of the body with the leads oriented caudally. The terminal end of the negative lead was tunneled subcutaneously from the abdominal incision toward the right pectoral muscle. The positive lead was tunneled subcutaneously from the abdominal incision to the left caudal rib region. The radiotransmitter was secured using a stay suture through the abdominal wall. All skin incisions were closed using 6-0 silk suture. After a 7-d recovery, heart rate, locomotor activity, and temperature were sampled for $10 \mathrm{~s}$ every $5 \mathrm{~min}$ over $60 \mathrm{~h}$. Activity was measured as the number of horizontal movements per minute.

After the baseline recordings, mice were injected once daily with one of the following medications (Sigma Chemical, St. Louis, MO): vehicle alone $(0.9 \% \mathrm{NaCl}, 10 \mathrm{ml} / \mathrm{kg})$, muscarinic receptor antagonists (atropine, $1 \mathrm{mg} / \mathrm{kg}$, or scopolamine, $2 \mathrm{mg} / \mathrm{kg}$ ), $\beta_{1}$-receptor antagonist (metoprolol, 
$4 \mathrm{mg} / \mathrm{kg}$ ), $\alpha_{1-}$ adrenergic receptor antagonist (prazosin, $2 \mathrm{mg} / \mathrm{kg}$ ), or nicotinic receptor antagonist (chlorisondamine, $2.5 \mathrm{mg} / \mathrm{kg}$ ). Responses were assessed at the plateau phase, $20-30 \mathrm{~min}$ after injection.

$H R V$. Using the $1,000-\mathrm{Hz}$ arterial blood pressure recordings or electrocardiogram recordings and HemoLab software (http://www.haraldstauss.com/HemoLab/HemoLab.php), HRV was evaluated according to the guidelines of the Task Force of the European Society of Cardiology $(44,45)$. Two separate 3 -min epochs were selected during a phase of inactivity to allow analysis of HRV in duplicate. For time domain analysis, beat-to-beat pulse intervals were used to calculate the SD of normalto-normal intervals, the square root of the mean squared differences of successive normal-to-normal intervals, and the total normal-to-normal intervals divided by the height of the histogram of all normal-to-normal intervals (Triangular Index). For frequency domain analysis, the same 3-min epochs were utilized to calculate power spectral density. Nonparametric spectral analysis was performed with the fast Fourier transformation technique to calculate absolute and relative power of the murine heart rate-specific VLF $(0.03-0.1 \mathrm{~Hz})$, low-frequency $(0.1-1.5$ $\mathrm{Hz})$, and high-frequency $(1.5-4.0 \mathrm{~Hz})$ spectral components.

Urinary noradrenaline excretion. While in metabolic cages, a 24-h urine sample was collected from adult male mice. Samples were acidified and stored at $-80^{\circ} \mathrm{C}$. Urinary excretion of noradrenaline was quantified by enzyme-linked immunosorbent assay (RE59261, IBL Hamburg, Hamburg, Germany).

Hematoxylin-eosin staining. Hearts were dissected and atria removed from mice that received the $5 \mathrm{mg} / \mathrm{kg} /$ day sertraline or saline from postnatal day 14 and $\geq 5$-mo-old adult hearts. Ventricles were washed with cold phosphate-buffered saline, then fixed in formalin overnight at $4^{\circ} \mathrm{C}$. Samples were embedded in paraffin, then sectioned ( $5 \mu \mathrm{m}$ thick) and stained with hematoxylin-eosin following standard protocols.

Serotonin transporter protein (5-HTT) and serotonin receptor expression. In adult male mice that received $5 \mathrm{mg} / \mathrm{kg} /$ day sertraline and control mice, the brain was quickly dissected, bluntly segmented, and stored in RNAlater (Qiagen, Valencia, CA) until purification with RNeasy kits (Qiagen). Initial coronal sectioning removed the olfactory bulbs anteriorly, as well as the cerebellum and medulla posteriorly. The remaining brain was then sectioned both superiorly and laterally to obtain a sample labeled "cortex" including both the cerebral cortex and pineal gland. The remaining segment, labeled "midbrain," included the dorsal raphe nucleus as well as the diencephalon (thalamus and hypothalamus). Finer dissection was not completed to avoid loss of information due to either passage of time or indiscriminate removal of grossly indistinct regions. RNA was quantitated using a NanoDrop ND-1000 spectrophotometer (Labtech International, East Sussex, UK). Reverse-transcription reactions were performed on $0.5 \mu \mathrm{g}$ total RNA with the addition of oligo dT, dNTPs, DTT, RNasin, and Superscript III reverse transcriptase (Invitrogen). Quantitative real-time reverse transcriptase PCR utilized the TaqMan reagent and instrumentation systems (Applied Biosystems, Foster City, CA). Taqman gene expression assay primer/probe sets for mouse 5-HTT (assay ID = Mm00439391_ $\mathrm{m} 1$ ) and 5- $\mathrm{HT}_{2 \mathrm{~B}}$ (assay ID = Mm00434123_m1) were purchased from Applied Biosystems. Given that the reaction efficiencies for the assays are matched by design, we used the $\Delta \Delta \mathrm{CT}$ method for quantitation.

Data analysis. All values other than reverse transcriptase PCR data are presented as means \pm SEM. Statistical comparisons were performed by two-tailed $t$-tests. Telemetry data were also compared by two-way repeated-measures ANOVA factoring for neonatal exposure (sertraline vs. saline) and time of day. Reverse transcriptase PCR data were compared by two-way repeated-measures ANOVA factoring for neonatal exposure (sertraline vs. saline) and brain region (midbrain vs. cortex). Post hoc analysis (Holm-Sidak test) was performed if statistically significant differences were detected. $P<0.05$ was considered significant.

\section{STATEMENT OF FINANCIAL SUPPORT}

This work was supported by the National Institutes of Health (grants HL07121, HL102659) and the Children's Miracle Network.

Disclosure: The authors declared no conflict of interest.

\section{REFERENCES}

1. IMS Health. National Prescription Audit. Parsippany, NJ: IMS, 2010.

2. Andrade SE, Raebel MA, Brown J, et al. Use of antidepressant medications during pregnancy: a multisite study. Am J Obstet Gynecol 2008;198:194. e1-5.

3. Bakker MK, Kölling P, van den Berg PB, de Walle HE, de Jong van den Berg LT. Increase in use of selective serotonin reuptake inhibitors in pregnancy during the last decade, a population-based cohort study from the Netherlands. Br J Clin Pharmacol 2008;65:600-6.

4. Oberlander TF, Warburton W, Misri S, Aghajanian J, Hertzman C. Neonatal outcomes after prenatal exposure to selective serotonin reuptake inhibitor antidepressants and maternal depression using populationbased linked health data. Arch Gen Psychiatry 2006;63:898-906.

5. Wichman CL, Fothergill A, Moore KM, Lang TR, Heise RH Jr, Watson WJ. Recent trends in selective serotonin reuptake inhibitor use in pregnancy. J Clin Psychopharmacol 2008;28:714-6.

6. Hendrick V, Stowe ZN, Altshuler LL, Hwang S, Lee E, Haynes D. Placental passage of antidepressant medications. Am J Psychiatry 2003;160:993-6.

7. Levinson-Castiel R, Merlob P, Linder N, Sirota L, Klinger G. Neonatal abstinence syndrome after in utero exposure to selective serotonin reuptake inhibitors in term infants. Arch Pediatr Adolesc Med 2006;160:173-6.

8. Moses-Kolko EL, Bogen D, Perel J, et al. Neonatal signs after late in utero exposure to serotonin reuptake inhibitors: literature review and implications for clinical applications. JAMA 2005;293:2372-83.

9. Greene MF. Teratogenicity of SSRIs-serious concern or much ado about little? N Engl J Med 2007;356:2732-3.

10. Oberlander TF, Eckstein Grunau R, Fitzgerald C, et al. Prolonged prenatal psychotropic medication exposure alters neonatal acute pain response. Pediatr Res 2002;51:443-53.

11. Oberlander TF, Grunau R, Mayes L, et al. Hypothalamic-pituitary-adrenal (HPA) axis function in 3-month old infants with prenatal selective serotonin reuptake inhibitor (SSRI) antidepressant exposure. Early Hum Dev 2008;84:689-97.

12. Oberlander TF, Grunau RE, Fitzgerald C, Papsdorf M, Rurak D, Riggs W. Pain reactivity in 2-month-old infants after prenatal and postnatal serotonin reuptake inhibitor medication exposure. Pediatrics 2005;115:411-25.

13. Ansorge MS, Morelli E, Gingrich JA. Inhibition of serotonin but not norepinephrine transport during development produces delayed, persistent perturbations of emotional behaviors in mice. J Neurosci 2008;28:199-207.

14. Shanahan NA, Holick Pierz KA, Masten VL, et al. Chronic reductions in serotonin transporter function prevent 5-HT1B-induced behavioral effects in mice. Biol Psychiatry 2009;65:401-8.

15. Maciag D, Simpson KL, Coppinger D, et al. Neonatal antidepressant exposure has lasting effects on behavior and serotonin circuitry. Neuropsychopharmacology 2006;31:47-57.

16. Nalivaiko E, Sgoifo A. Central 5-HT receptors in cardiovascular control during stress. Neurosci Biobehav Rev 2009;33:95-106.

17. Krystal JH, Neumeister A. Noradrenergic and serotonergic mechanisms in the neurobiology of posttraumatic stress disorder and resilience. Brain Res 2009;1293:13-23.

18. Louik C, Lin AE, Werler MM, Hernández-Díaz S, Mitchell AA. First-trimester use of selective serotonin-reuptake inhibitors and the risk of birth defects. N Engl J Med 2007;356:2675-83.

19. Kornum JB, Nielsen RB, Pedersen L, Mortensen PB, Nørgaard M. Use of selective serotonin-reuptake inhibitors during early pregnancy and risk of congenital malformations: updated analysis. Clin Epidemiol 2010;2:29-36.

20. Merlob P, Birk E, Sirota L, et al. Are selective serotonin reuptake inhibitors cardiac teratogens? Echocardiographic screening of newborns with persistent heart murmur. Birth Defects Res Part A Clin Mol Teratol 2009;85:837-41.

21. Pedersen LH, Henriksen TB, Vestergaard M, Olsen J, Bech BH. Selective serotonin reuptake inhibitors in pregnancy and congenital malformations: population based cohort study. BMJ 2009;339:b3569.

22. Sari Y, Zhou FC. Serotonin and its transporter on proliferation of fetal heart cells. Int J Dev Neurosci 2003;21:417-24. 
23. Noorlander CW, Ververs FF, Nikkels PG, van Echteld CJ, Visser GH, Smidt MP. Modulation of serotonin transporter function during fetal development causes dilated heart cardiomyopathy and lifelong behavioral abnormalities. PLoS ONE 2008;3:e2782.

24. Clubb FJ Jr, Bishop SP. Formation of binucleated myocardial cells in the neonatal rat. An index for growth hypertrophy. Lab Invest 1984;50:571-7.

25. Walsh S, Pontén A, Fleischmann BK, Jovinge S. Cardiomyocyte cell cycle control and growth estimation in vivo-an analysis based on cardiomyocyte nuclei. Cardiovasc Res 2010;86:365-73.

26. Thayer JF, Yamamoto SS, Brosschot JF. The relationship of autonomic imbalance, heart rate variability and cardiovascular disease risk factors. Int J Cardiol 2010;141:122-31.

27. Ungvari Z, Pacher P, Koller A. Serotonin reuptake inhibitor fluoxetine decreases arteriolar myogenic tone by reducing smooth muscle [Ca2+]i. J Cardiovasc Pharmacol 2000;35:849-54.

28. Côté F, Fligny C, Fromes Y, Mallet J, Vodjdani G. Recent advances in understanding serotonin regulation of cardiovascular function. Trends Mol Med 2004; 10:232-8.

29. Nebigil CG, Choi DS, Dierich A, et al. Serotonin 2B receptor is required for heart development. Proc Natl Acad Sci USA 2000;97:9508-13.

30. Nebigil CG, Hickel P, Messaddeq N, et al. Ablation of serotonin 5-HT(2B) receptors in mice leads to abnormal cardiac structure and function. Circulation 2001;103:2973-9.

31. Brocco M, Dekeyne A, Veiga S, Girardon S, Millan MJ. Induction of hyperlocomotion in mice exposed to a novel environment by inhibition of serotonin reuptake. A pharmacological characterization of diverse classes of antidepressant agents. Pharmacol Biochem Behav 2002;71:667-80.

32. Kummet GJ, Haskell SE, Hermann GM, et al. Neonatal SSRI exposure programs a hypermetabolic state in adult mice. J Nutr Metab 2012;2012: 431574.

33. Zeskind PS, Stephens LE. Maternal selective serotonin reuptake inhibitor use during pregnancy and newborn neurobehavior. Pediatrics 2004;113:368-75.

34. Muneoka K, Shirayama Y, Takigawa M, Shioda S. Brain region-specific effects of short-term treatment with duloxetine, venlafaxine, milnacipran and sertraline on monoamine metabolism in rats. Neurochem Res 2009;34:542-55.
35. Halberstadt AL, van der Heijden I, Ruderman MA, et al. 5-HT(2A) and $5-\mathrm{HT}(2 \mathrm{C})$ receptors exert opposing effects on locomotor activity in mice. Neuropsychopharmacology 2009;34:1958-67.

36. Thornburg K, Jonker S, O'Tierney P, et al. Regulation of the cardiomyocyte population in the developing heart. Prog Biophys Mol Biol 2011;106:289-99.

37. Bergmann O, Bhardwaj RD, Bernard S, et al. Evidence for cardiomyocyte renewal in humans. Science 2009;324:98-102.

38. Johnson RD, Lewis RJ, Angier MK. The distribution of fluoxetine in human fluids and tissues. J Anal Toxicol 2007;31:409-14.

39. Reis M, Aamo T, Spigset O, Ahlner J. Serum concentrations of antidepressant drugs in a naturalistic setting: compilation based on a large therapeutic drug monitoring database. Ther Drug Monit 2009;31:42-56.

40. Kelly RH, Russo J, Holt VL, et al. Psychiatric and substance use disorders as risk factors for low birth weight and preterm delivery. Obstet Gynecol 2002;100:297-304.

41. Lang RM, Bierig M, Devereux RB, et al. Recommendations for chamber quantification: a report from the American Society of Echocardiography's Guidelines and Standards Committee and the Chamber Quantification Writing Group, developed in conjunction with the European Association of Echocardiography, a branch of the European Society of Cardiology. J Am Soc Echocardiogr 2005;18:1440-63.

42. Kronik G, Slany J, Mösslacher H. Comparative value of eight M-mode echocardiographic formulas for determining left ventricular stroke volume. A correlative study with thermodilution and left ventricular singleplane cineangiography. Circulation 1979;60:1308-16.

43. Roghair RD, Segar JL, Volk KA, et al. Vascular nitric oxide and superoxide anion contribute to sex-specific programmed cardiovascular physiology in mice. Am J Physiol Regul Integr Comp Physiol 2009;296:R651-62.

44 Heart rate variability: standards of measurement, physiological interpretation and clinical use. Task Force of the European Society of Cardiology and the North American Society of Pacing and Electrophysiology. Circulation 1996;93:1043-65.

45. Stauss HM. Identification of blood pressure control mechanisms by power spectral analysis. Clin Exp Pharmacol Physiol 2007;34:362-8. 